\title{
Evolution in the Museum
}

\author{
Monique Scott
}

Published online: 14 April 2012

(C) Springer Science+Business Media, LLC 2012

From the emergence of the natural history museum in the late nineteenth century, it has been a critical and powerful vehicle for disseminating evolution to the public. Natural history museums largely emerged to espouse the tenets of Darwinism, and they continue that legacy as evolution continues to cohere almost all of the research, exhibition, and education that happen in museums today.

This issue is not only a celebration of Darwinism in the museum, but also a celebration of how museums globally find challenging and creative ways to present evolution to its many, disparate publics. To celebrate and critique the role of the museum in evolutionary education, the papers in this special issue represent an important cross-section of thinking about evolution in museums. There also is great variation in the voices, content, and style that contribute to this special issue, a reflection of the varied nature of thinking about museums - from descriptions of novel exhibition designs to pedagogical analyses on visitors' interpretations in the museum. From the array of articles presented in this issue, you can see the diversity of critical epistemological and pedagogical strategies employed by museums to engage the public in new ways of understanding evolutionary theory, biodiversity, and the relationship between humans and the natural world.

As mentioned, several articles illustrate new innovative approaches museums use to introduce, or reintroduce, evolution to the public. The exhibition perspectives are as farreaching from history of science to modern art, from Dominici's article about an exhibition celebrating geology, deep time, and a historic collection at the Museum of Natural History at the University of Florence to Bloomfield's paper on the innovative

\footnotetext{
M. Scott $(\bowtie)$

American Museum of Natural History,

New York, NY, USA

e-mail: mscott@amnh.org
}

art installation at the Natural History Museum in London celebrating the bicentenary of Charles Darwin and the sesquicentennial of The Origin of Species. William Harcourt Smith's essay illustrates for us how the Hall of Human Origins exhibition at the American Museum of Natural History Museum strategically interweaves two lines of data, genetic and fossil, to shed new light on an old topic. And Bruce MacFadden addresses the ways old exhibition habits die hard in his exploration of orthogenesis and the evolution of horses in museums.

Several papers also bridge the elusive gap between museum exhibition and museum education, or how evolutionary education is actually received by a museum's audiences and particularly youth. Jane Pickering's essay poignantly bridges this gap between exhibition and education. She provides an in-depth look into the Yale Peabody Museum's efforts to use human health as a platform for teaching about evolution and biodiversity through exhibition in the museum and education in the classroom. Other papers offer critical windows into their evolutionary education strategies. Honor Gay's essay discusses novel education efforts that involve training museum volunteers to have challenging but important "learning conversations" with visitors to galleries. And Falcetti uses new participatory and interactive techniques to challenge audiences' preconceptions of evolution in the Zoological Museum of Rome.

It is not surprising that a significant subset of conversation about evolutionary education in the museum concerns "treethinking" - or the ever-significant growth of research investigating how laypersons understand and interpret evolutionary trees, and the underpinning methodology and philosophy behind systematics. Tree-thinking has become an important metaphor and tool to enhance museum visitors' understanding of science and the natural world; and it encourages the public to understand evolution and their relationship to it in new critical ways. Two papers in this issue contribute significantly to the conversation about trees and tree-thinking. In this issue, 
MacDonald et al. present their robust analysis of 185 tree of life graphics from 52 museum sites in an analysis of how those evolutionary trees depicted in informal science settings actually communicate the science of phylogenetics to the public. Giusti evaluated how visitors grasped concepts big and small in a traveling exhibition specifically about cladistics and evolutionary trees, "Travels in the Great Tree of Life."

Critical conversations have been happening for the last several decades around how museum visitors actually understand the process of evolution. As the Giusti and MacDonald articles attest, this issue also contributes to a thriving industry of museum evaluation information and benefits from papers by leaders in that field. The Spiegel et al. paper represents the height of this form of research. The authors rigorously investigated how visitors' causal explanations about biological change, drawn from three reasoning patterns (evolutionary, intuitive, and creationist), were modified as a result of visiting an evolution exhibition. Clearly, while the museum continues to be a site for the production of evolutionary information and dissemination of that information through exhibition, it is also a site for increasingly important critical research into evolutionary education.

As an ardent lover of museums myself, and as someone who has devoted her career to evolutionary education in museums, I believe there are few places that can simultaneously inspire as much wonder and impart as much critical scientific knowledge as the natural history museum. And while the gorgeous array of flora and fauna that museums display are a testament to the wonder of evolution, it is through evolution, and often its embodiment in The Tree of Life that really captures and communicates the immense spectrum and dynamism of evolution. If we can teach visitors to understand evolution, we teach them to really understand the interconnectedness of life, as well as the interconnectedness of the scientific disciplines that produce evolutionary knowledge. Evolution places the world - and the museum's cases of lizards, sparrows, cichlids, dinosaurs, and hominids - in perspective. And evolutionary perspective, with its implications for everything from conservation to human health, is perhaps the museum's greatest contribution to the world. 